\title{
Determinació de la massa molecular d'un líquid
}

\author{
Montserrat Tortosa Moreno \\ IES Ferran Casablancas (Sabadell) \\ mtortosa@xtec.net
}

Es tracta de determinar la massa molar d'un líquid volàtil fent-ne vaporitzar una massa coneguda dins d'un recipient tancat, mesurant les corresponents pressió i temperatura.

\section{INTRODUCCIÓ}

La massa molar d'una substància pot determinar-se dividint la seva massa, en grams, pel nombre de mols que conté.

En aquesta pràctica es determina la massa molar de l'acetona de la següent manera:

- S'agafa un erlenmeyer buit i es mesura el seu volum, la pressió i la temperatura. Amb aquestes dades pot trobar-se el nombre de mols de gas que hi ha a l'erlenmeyer, deguts a l'aire que conté. Convé no tocar gaire l'erlenmeyer per no fer-ne variar la temperatura.

- Es posa un volum concret d'acetona dins l'erlenmeyer. L'acetona és una substància pura líquida a temperatura ambient de densitat 0,79 $\mathrm{g} / \mathrm{cm}^{3}$. Amb la densitat, podem calcular la massa de l'acetona, ja que densitat = massa/volum. (la massa també es podria determinar amb una balança).

- Es tapa l'erlenmeyer amb un tap connectat a un sensor de pressió i el conjunt es submergeix en un bany d'aigua calenta $\left(55-65^{\circ} \mathrm{C}\right)$, amb un sensor de temperatura es sap el valor concret. L'acetona es vaporitza i la pressió augmenta. A partir de les dades de pressió i temperatura màxims es pot trobar el nombre de mols de gas que conté ara l'erlenmeyer. Si restem el nombre de mols de gas que hi havia inicialment deguts a l'aire, obtenim els mols d'acetona.

- Finalment, quan ja tinguem els grams i els mols, calcularem la massa molar.

\section{MATERIAL I EQUIPAMENT}

\section{Material de laboratori}

- Vas de precipitats de $500 \mathrm{ml}$

- Erlenmeyer de $100 \mathrm{ml}$

- Tap de goma per a l'erlenmeyer, travessat amb una agulla hipodèrmica.

- Suport, pinces i nou.

- Resistència calefactora o bec bunsen.

- Pipeta

- Proveta de $250 \mathrm{ml}$

- Vas de precipitats petit

\section{Productes}

- Aigua de l'aixeta

- Acetona
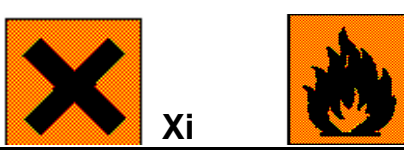

Elements equip Multilog

- Interfícies Multilog-Pro amb cables USB

- Sensors de temperatura (rang $-25^{\circ} \mathrm{C} / 110^{\circ} \mathrm{C}$, resolució $0,13^{\circ} \mathrm{C}$ ) i de pressió (rang 0 - 700 $\mathrm{kPa}$, resolució $0,5 \mathrm{kPa}$ )

- Ordinador 


\section{PROCEDIMENT}

\section{Muntatge de l'experiència}

Abans de començar la pràctica, cal fer les operacions següents:

\section{Determinar el volum de l'erlenmeyer}

Ompliu l'erlenmeyer amb aigua de l'aixeta i aboqueu el contingut dins d'una proveta.

Anoteu el resultat. Cal assecar bé l'erlenmeyer abans d'utilitzar-lo per a la pràctica.

\section{Mesurar el volum exacte d'una gota d'acetona}

Poseu una mica (uns $5 \mathrm{ml}$ ) d'acetona dins d'un vas de precipitats petit. Pipetegeu una mica d'acetona amb la pipeta, i deixeu-ne caure 40 gotes i mesureu el volum exacte que ocupen. Repetiu el procediment dues vegades més i calculeu el valor mig del volum d'una gota.

\section{Preparar un bany d'aigua calenta}

Agafeu un vas de precipitats de $500 \mathrm{ml}$, l'ompliu d'aigua de l'aixeta fins a tres quartes parts i l'escalfeu amb el bunsen fins uns $60 \circ 70^{\circ} \mathrm{C}$. També pot escalfar-se amb una resistència elèctrica.

\section{Connectar el tap al sensor de pressió}

Ajusteu el sensor de pressió a l'agulla hipodèrmica del tap de goma.

\section{Adquisició i enregistrament de les dades}

1) Configureu el programa per mesurar pressió i temperatura en funció del temps (vegeu l'apartat "Configuració del programa", més avall).

2) Agafeu el sensor de temperatura i poseu-lo dins del vas de precipitats que conté l'aigua escalfada prèviament de manera que la punta del sensor toqui l'aigua, però no el vas. Podeu ajudarvos d'un suport i una pinça.

3) Amb una pipeta, poseu quatre gotes d'acetona dins de l'erlenmeyer (cal que estigui ben sec), immediatament tapeu-lo amb un tap connectat al sensor de pressió. (cal fer aquesta operació ben ràpid perquè l'acetona s'evapora ràpidament)

4) Inicieu la captació, cliqueu el botó Executar (*) immediatament poseu l'erlenmeyer tapat dins del vas de manera que quedi envoltat d'aigua calenta (fig. 1).

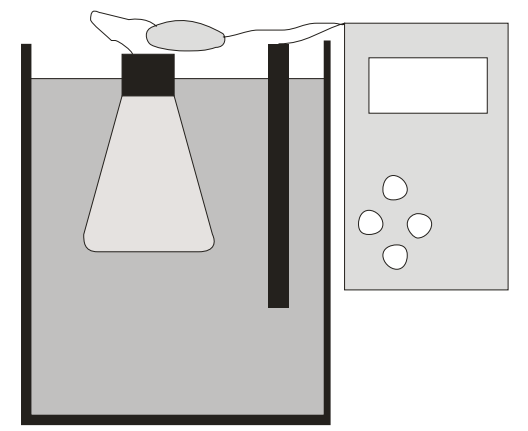

Figura 1. Esquema del muntatge experimental per a la determinació de la massa molar de líquids volàtils.

5) Continueu la presa de dades fins que comencin a disminuir els valors tant de pressió com de temperatura (cal tenir present que el sensor de temperatura és més lent de resposta que el de pressió, que té un temps de resposta d'un mil.lisegon)

6) Per finalitzar la captació, cliqueu el botó Stop. (ㄹ)

7) Feu un gràfic amb la variació de la pressió i la temperatura. Guardeu-lo

8) Anomeneu i guardeu l'arxiu amb l'opció guardar com del menú arxiu.

COMPTE!, si feu proves amb altres
quantitats:
Aquest muntatge aguanta bé una
pressió d'uns $150 \mathrm{kPa}$.
A pressions superiors pot saltar el tap
si no es subjecta.

\section{Orientacions tècniques}

$\mathrm{Hi}$ ha dos factors clau per tal que la pràctica doni resultats acceptables:

- No tocar l'erlenmeyer abans de tirar l'acetona, pot dilatar i fer sortir aire de dins.

- Tapar l'erlenmeyer immediatament després d'haver tirat les gotes d'acetona, si no es fa part de l'acetona s'evapora.

Seria ideal que el sensor de temperatura pogués estar a dins de l'erlenmeyer, però no s'ha trobat la manera de mantenir el compartiment estanc amb aquest sensor a l'interior; tot $i$ així en submergir el conjunt en aigua calenta, s'escalfa també la part interior de l'erlenmeyer. Els resultats obtinguts són acceptables. 
Cal vigilar amb la quantitat de líquid que vaporitza, perquè aquest muntatge no aguanta una pressió superior a $150 \mathrm{kPa}$. A pressions superiors el tap salta a no ser que es subjecti fortament. Per evitar accidents es recomana no treballar a pressions superiors a aquest valor.

\section{CONFIGURACIÓ DEL PROGRAMA}

És convenient fer l'experiència per triplicat per tal de minimitzar els errors

1) Connecteu el sensor de temperatura a la consola Multilog (interfície), a l'entrada IO-1

2) Connecteu els sensor de pressió a la consola Multilog a l'entrada IO-2

3) Connecteu la interfície a l'ordinador.

4) Obriu la interfície i després l'ordinador.

5) Obriu el programa Multilab.

6) Heu de mesurar les dades de temperatura i de pressió inicials, per tal de poder determinar l'aire que conté inicialment l'erlenmeyer. Podeu agafar la configuració que dóna el programa per defecte.

- Col-loqueu el sensor de temperatura dins l'erlenmeyer buit. Cliqueu el botó Executar ( $x^{*}$ ). Anoteu les dades de temperatura i pressió inicials. Anomeneu i guardeu l'arxiu amb l'opció guardar com del menú arxiu.

- No toqueu l'erlenmeyer per no fer-li variar la temperatura.

En el menú obrir, trieu nou projecte. Caldrà configurar el sistema.

A partir d'aquest moment és important no tocar l'erlenmeyer ni tenir-lo prop de cap font de calor.

7. Configuració del sistema. Cliqueu el botó configurar ajudant, "荁. S'obren tres pantalles successives:

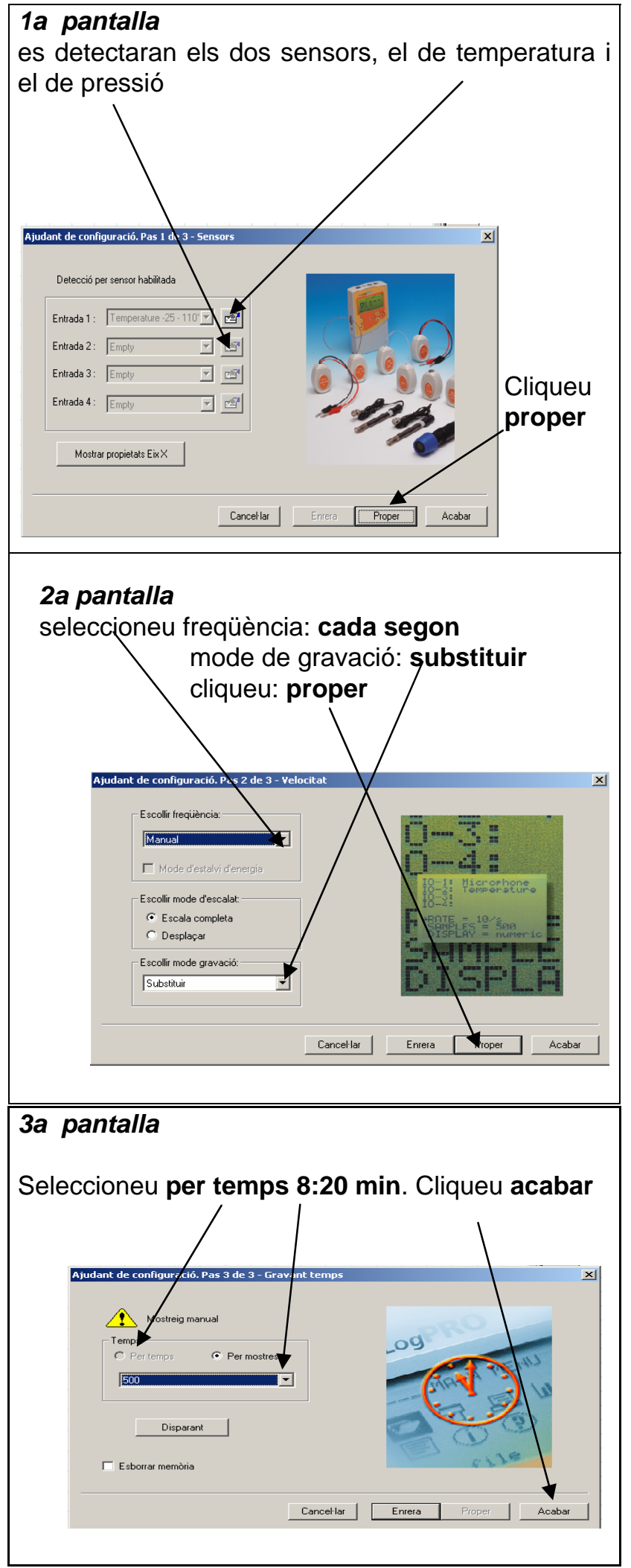




\section{RESULTATS OBTINGUTS}

\section{Mesures prèvies}

Mesura del volum de l'erlenmeyer: $125 \mathrm{~mL}$

Volum d'una gota d'acetona amb la pipeta emprada, que és de $2 \mathrm{~mL}$ de capacitat màxima

\begin{tabular}{|c|r|}
\hline nombre de gotes & Volum total $(\mathrm{mL})$ \\
\hline 40 & 0,85 \\
\hline 40 & 0,86 \\
\hline 40 & 0,87 \\
\hline
\end{tabular}

Utilitzem la relació $0,86 \mathrm{~mL} / 40$ gotes per passar de gotes a volum en $\mathrm{mL}$, que és el valor mig.

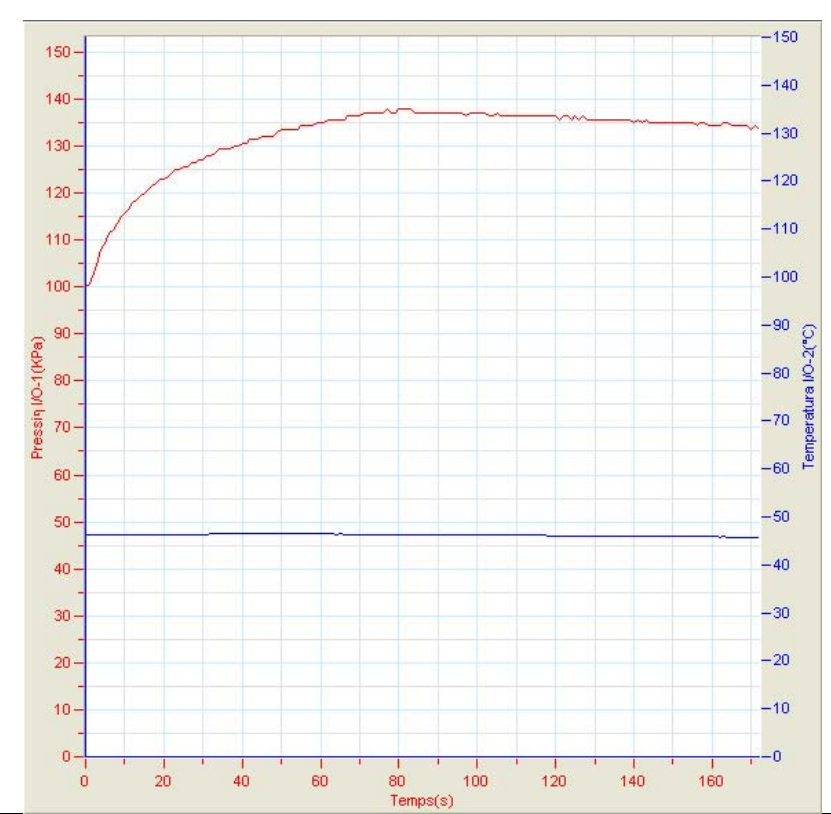

Figura 2. Gràfiques obtingudes en fer vaporitzar 5 gotes d'acetona.

\section{Tractament i anàlisi de les dades}

Calculeu el nombre de mols $\left(\mathrm{n}_{0}\right)$ d'aire que conté inicialment l'erlenmeyer. Utilitzeu l'equació dels gasos ideals, les dades de pressió i temperatura inicials i el volum de l'erlenmeyer.

Pressió ambiental $=97,1 \mathrm{kPa}$

Temperatura ambiental $=20,3^{\circ} \mathrm{C}$

$n_{0}=P \cdot V / R \cdot T=4,98 \cdot 10^{-3}$ mols inicials de gas a l'erlenmeyer

Agafeu les dades de pressió i temperatura màximes (figura 2), obtingudes en vaporitzar l'acetona, calculeu el nombre de mols de gas presents a l'erlenmeyer. Aquests corresponen a l'acetona i a l'aire.

$T$ màxima $=46,5^{\circ} \mathrm{C}$

$P$ màxima $=137,9 \mathrm{kPa}$

$n_{\text {total }}=6,49 \cdot 10^{-3} \mathrm{~mol}$

Calculeu els mols d'acetona vapor.

Mol acetona vap $=n_{\text {total }}-n_{o}=1 \cdot 51.10^{-3} \mathrm{~mol}$

Calculeu la massa d'acetona que ha vaporitzat a partir del nombre de gotes que heu posat, del volum que tenen les gotes i de la densitat.

Massa acetona: 5 gotes $\cdot(0,86 \mathrm{~mL} / 40$ gotes $)$. $(0,79 \mathrm{~g} / 1 \mathrm{ml})=0,0849 \mathrm{~g}$

Calculeu la massa molar de l'acetona.

$\mathrm{M}$ molar acetona $=$ massa acetona $/ \mathrm{mol}$ acetona $=$ $0,0849 / 1,51 \cdot 10^{-3}=56,2 \mathrm{~g} / \mathrm{mol}$

Quina és la massa molar real de l'acetona? Determineu el \% d'error de la vostra mesura.

$M$ molar real acetona $=58,1 \mathrm{~g} / \mathrm{mol}$

\%error $=((58,1-56,2) / 58,1) \cdot 100=3,3 \%$

\section{Nota}

Aquest protocol és part del treball realitzat durant una llicència d'estudis concedida pel Departament d'Educació el curs 2004-2005. 